Etnográfica

Revista do Centro em Rede de Investigação em

Antropologia

vol. $23(3) \mid 2019$

Vol. 23 (3)

\title{
Açúcar, ananases e ilhéus portugueses no Hawaii: dinâmicas de migração, etnicidade e racialização no terreno e no arquivo
}

Sugar, pineapples and Portuguese islanders in Hawaii: studying migration, ethnicity and racialization in the field and in the archive

\section{Cristiana Bastos}

\section{(2) OpenEdition}

\section{Journals}

\section{Edição electrónica}

URL: https://journals.openedition.org/etnografica/7674

DOI: 10.4000/etnografica.7674

ISSN: 2182-2891

\section{Editora}

Centro em Rede de Investigação em Antropologia

\section{Edição impressa}

Data de publição: 1 outubro 2019

Paginação: 777-798

ISSN: 0873-6561

\section{Refêrencia eletrónica}

Cristiana Bastos, «Açúcar, ananases e ilhéus portugueses no Hawaii: dinâmicas de migração, etnicidade e racialização no terreno e no arquivo», Etnográfica [Online], vol. 23 (3) | 2019, posto online no dia 28 novembro 2019, consultado o 19 janeiro 2022. URL: http://journals.openedition.org/ etnografica/7674 ; DOI: https://doi.org/10.4000/etnografica.7674

\section{(c) (7) (8)}

Etnográfica is licensed under a Creative Commons Attribution-NonCommercial 4.0 International License. 


\section{Açúcar, ananases e ilhéus portugueses no Hawaii: dinâmicas de migração, etnicidade e racialização no terreno e no arquivo}

\section{Cristiana Bastos}

Após uma revisão das combinações terreno-arquivo em trabalhos prévios, abordo as migrações de madeirenses e açorianos para o Hawaii. Contrasto um tema da oralidade, que as associa à familiaridade com o cultivo de açúcar na Madeira e de ananases nos Açores, com os resultados da pesquisa documental, que permitem situar esta migração num contexto de economia de plantação com necessidades de trabalho intensivo - num primeiro momento sob uma monarquia indígena cosmopolita a braços com o declínio demográfico e políticas de repovoamento através da migração, e, num segundo momento, enquanto território anexado a uma das novas potências do século XX, os EUA. No conjunto, perto de 20 mil ilhéus portugueses migraram para o Hawaii e ali constituíram sociedade, recortando uma das identificações de ancestralidade reconhecidas, separadas e discutidas nos estudos de etnicidade. Sugiro que esta discussão ajuda a ultrapassar alguns fechamentos da escola sociológica de Chicago e estudos de etnogénese produzidos até hoje, propondo em alternativa um estudo das dinâmicas de racialização hierarquizada pela posição no trabalho.

PALAVRAS-CHAVE: migração, plantação, trabalho, Madeira, Açores, Hawaii.

Sugar, pineapples and Portuguese islanders in Hawaii: studying migration, ethnicity and racialization in the field and in the archive - After reviewing field-archive combinations in previous research, I address Madeiran and Azorean migration to Hawaii. I discuss the contrast between the orally-transmitted theme that connects their migration to their familiarity of sugar cane and pineapple growing and what emerges from the archive, which indicates that it occurred in the context of a labor-intensive sugar plantation economy both under indigenous Hawaiian cosmopolitan monarchy and after annexation to the USA. In the end, almost 20,000 Portuguese islanders moved to Hawaii and made society there, shaping one distinct identification and ancestry group, thoroughly addressed by Chicago school sociologists and ethnicity scholars. I conclude suggesting to overcome current limitations in ethnicity/ethnogenesis studies by focusing on the hierarchized dynamics of racialization operated by the plantation system and its labor hierarchies.

KEYWORDS: migration, plantation, labor, Madeira, Azores, Hawaii.

BASTOS, Cristiana (cristiana.bastos@ics.ulisboa.pt) - Instituto de Ciências Sociais, Universidade de Lisboa, Portugal.

[Nota] Por opção da autora, o artigo é publicado usando a ortografia anterior à estabelecida pelo Acordo Ortográfico de 1990 e é usada a grafia Hawaii (aproximação do original Hawai ii), e não Havai. 


\section{ENCONTROS DE ANTROPOLOGIA E HISTÓRIA}

O que apresento hoje resulta de uma pesquisa que combina terreno e arquivo. ${ }^{1}$ Não querendo fazer proselitismo sobre este modo de investigar, é nele que mais acredito, independentemente das flutuações nas modas teóricas e metodológicas da disciplina; e é a esta prática que recorro desde que faço antropologia, usando à medida de cada caso uma proporção diferente de arquivo e de trabalho de campo. Nalgumas investigações dei mais ênfase à ancoragem empírica no terreno imediato, na escuta, observação, participação na vida social; nessas ocasiões, o arquivo trazia espessura ao compósito interpretativo da realidade a que chamamos etnografia. Noutros casos aproximei-me de realidades sociais do passado nas quais não são possíveis a escuta e observação directas, pelo que me ancorei em arquivos, colecções, documentos, enfim, materialidades que requerem modos especiais de escuta e observação, mas podem ainda ser trabalhados etnograficamente.

Há muito que alguns de nós visitam o arquivo com atitude etnográfica, ou seja, encarando os documentos com a mesma postura de escuta e observação que se leva para o terreno, guiada por questões, procurando nexos, praticando a inquietação interpretativa, e fugindo do amassar amorfo de dados em listagens que se aceita em algumas outras disciplinas. E acrescente-se que, em alguns casos, a inquietação interpretativa obriga também a ir ao lugar físico onde decorreu a vida social que procuramos interpretar a partir do arquivo, mesmo que nesse lugar já não esteja ninguém, mesmo que pareça não haver sinais e testemunhos do que procuramos - eles estão lá sempre, e recomenda-se também sempre a ida ao local, mesmo que este seja de paisagens inteiramente

I Este texto foi inicialmente apresentado oralmente no dia 24 de Outubro de 2018 como Aula Ernesto Veiga de Oliveira, organizada pelo Departamento de Antropologia do ISCTE - Instituto Universitário de Lisboa e dirigida especialmente aos novos alunos do curso de licenciatura em Antropologia. Agradeço aos colegas desse departamento, em particular a Miguel Vale de Almeida, o honroso convite para a proferir, e ao público então presente agradeço a excelente discussão proporcionada. A investigação foi desenvolvida no âmbito do projecto "The Colour of Labour: The Racialized Lives of Migrants", que submeti em 2015 ao Conselho Europeu de Investigação (ERC - European Research Council) e com o qual obtive a Advanced Grant 695573. Agradeço ao ERC o generoso apoio e reconhecimento; ao ICS-ULisboa, a liberdade de investigação ao longo dos anos; às instituições de acolhimento no Hawaii, East-West Center e University of Hawaii at Manoa; aos interlocutores permanentes da Portuguese Genealogical and Historical Society of Hawaii; Plantation Village, Waipahu; Plantation Museum, Papaikou; Portuguese Heritage and Cultural Center, Maui; Holy Ghost Society of Punchbowl, Honolulu; Centro de Estudos de História Atlântica, Funchal; aos responsáveis e funcionários de inúmeros arquivos e bibliotecas - Hawaii State Archives; Hawaiiana and Pacific Collection, Hamilton Library, UH Manoa; Bishop Museum; Hawaiian Historical Society; Arquivo Distrital da Madeira; Arquivo Histórico Ultramarino; Arquivo Histórico Diplomático do Ministério dos Negócios Estrangeiros, Caird Library, National Maritime Museum, Greenwhich, UK; The National Archives, UK; British Library. Agradeço aos membros da equipa do projecto "Colour of Labour" as discussões e reflexões. Finalmente, agradeço a Manuela Ivone Cunha e Catarina Mira, da Etnográfica, o estímulo para verter a palestra em artigo. 
transformadas ou de puras ruínas e entulho (Gordillo 2014). A experiência física do lugar dá-nos muito da materialidade das circunstâncias em que ocorreram as vidas e entrosamentos sociais que procuramos interpretar - o clima, a altitude, a orografia, a luz, outras permanências; para além disso, podem surgir testemunhos que o texto aplanado e racionalizado dos documentos não deixaria prever.

Ficará para outro momento uma discussão mais aprofundada do que veio a ser referido como archival turn, que afectou de diferentes modos a antropologia e a história, trazendo a esta uma problematização dos seus métodos e objectos e àquela uma expansão do seu horizonte de pesquisa (e.g., Stoler 1995, 2010; Ladwig et al. 2012). Por ora, fiquemos com alguns exemplos que colho da minha experiência.

\section{PRIMEIROS ENCONTROS E A CONSTATAÇÃO DOS DESENCONTROS:} BARRANCOS E SERRA ALGARVIA

Ainda com a licenciatura por terminar e no que era então um rito de passagem que consistia em atirar-nos para o terreno para aprender a etnografar, inteirei-me do desencontro entre o que chega à memória colectiva e o que está fixado na documentação. Em Barrancos, na fronteira de Portugal e Espanha, mantinha a história oral que a vila nascera de um exílio dos habitantes do vizinho castelo de Noudar, fugindo a epidemias, febres e outras insalubridades do lugar. Asserção verosímil, dado que Noudar correspondia a ruínas, evocando o passado, e Barrancos era uma vila pujante do presente. Mas quando, inexperiente e ignorante, procurei na documentação dados sobre as circunstâncias de tal exílio, os possíveis anos das febres, as decisões ponderadas, os ritmos e os actores da mudança, verifiquei não só que nada se encontrava sobre o assunto - sem que tal invalide que possam ter existido epidemias e exílio -, mas também que a povoação de Barrancos afinal preexistia à de Noudar. A minha perplexidade não durou muito; não é à toa que nos formamos em antropologia e somos expostos às variantes mais complexas da criatividade humana, que aprendemos que mitos, lendas e narrativas não são "falsidades", mas modos de contar, que os modos de contar flutuam e variam e que podem constituir-se em sistemas de transformações, como nos ensinam o estudo das mitologias ameríndias feitos por Lévi-Strauss (1964-1971) a partir das recolhas de Nimuendaju e, mais perto de nós, o estudo dos contos de fadas (e.g., F. V. Silva 2016).

A história de um exílio de um castelo original podia ser vista como um mito de origem; e já ali chegara a partir de um outro, contado mais a norte, em Monsaraz, que referia uma troca desigual entre portugueses e espanhóis, ou de como uma simples vila espanhola como Barrancos teria sido trocada pela nobre cidade portuguesa de Olivença, para gáudio dos espanhóis e azar dos 
portugueses. ${ }^{2}$ Também para esta "troca" não existia suporte documental. Tratava-se de uma alocução que, como a antropologia aprendeu da psicanálise e disciplinas vizinhas, subtrai e acrescenta à factualidade exterior elementos que provêm de um registo identitário; nas narrativas de exílio e troca estavam contidos, sem necessidade de contrapartida factual, vários significados relevantes para a auto-imagem colectiva - antepassados num castelo, dupla identificação com Portugal e Espanha. Afinal, o estudo dos mitos de origem ameríndios tinha-me permitido ampliar as chaves interpretativas. Esse é um caminho sem volta, essa chave ajuda-nos a perceber muito do que nos rodeia hoje, no terreno e em casa, e daqui a pouco voltarei ao tema a propósito dos discursos de nação, império e migração. Antes disso, um pouco mais de retrospectiva às minhas andanças na díade terreno-arquivo, pois foi delas que nasceu o tema de hoje.

O meu segundo trabalho de pesquisa etnográfica prolongou essa combinação de terreno e arquivo em outro contexto, o da serra algarvia (Bastos 1993). Seguindo o que era então uma tendência importante na antropologia portuguesa, de articulações com a micro-história de dinâmicas familiares - como faziam, entre outros, Robert Rowland, Norberta Araújo, Brian O’Neill, Raúl Iturra e José Manuel Sobral e, a partir de Oxford, João de Pina Cabral -, introduzi uma pequena diferença, apoiada pelo meu então orientador de mestrado, Vitorino Magalhães Godinho, que foi a de ampliar a unidade de análise para constelações de lugares e não me ater às pequenas unidades que eram os "montes". ${ }^{3}$

Encontrei ampla documentação sobre o local e no local, incluindo róis de confessados e livros de visitações amontoados nos anexos da igreja de Martinlongo, que permitia estabelecer nexos interpretativos com a oralidade e não eram dela discordantes. Pelo contrário: os planos oral e documental elucidavam-se mutuamente. $\mathrm{O}$ que não se articulava com estes nexos era o aparato discursivo oficial sobre a inviabilidade da vida na serra, desenvolvido a partir de uma perspectiva litoral e desenvolvimentista. A contradição estava entre a vida social que persistia e o discurso estabelecido que a negava, assente em pesquisas técnicas que davam prioridade ao reflorestamento.

\section{DO MUITO LOCAL AO GLOBAL GERAL}

Um terceiro momento de pesquisa corresponde a uma grande viragem na minha trajectória. Tinha ido para os Estados Unidos nos finais da década de 1980 com o intuito de aprofundar a análise do extenso material empírico que tinha

2 Estes dados foram recolhidos em Monsaraz e Barrancos em 1982, durante uma viagem exploratória no âmbito da licenciatura em Antropologia na Faculdade de Ciências Sociais e Humanas da Universidade Nova de Lisboa.

3 Agradeço a Robert Rowland e demais colegas do núcleo de demografia histórica do Instituto Gulbenkian de Ciência o convite para os seminários e apoio metodológico, e a João Pina Cabral a confiança depositada. 
recolhido na serra algarvia e não explorara no âmbito do mestrado. Uma vez aí, dediquei-me porém a algo que sempre me chamara, mas não tivera antes ocasião de explorar: a antropologia médica ou da saúde, feita em combinação com os então nascentes estudos sociais de ciência e com a também nascente antropologia dos processos globais. Estudei a epidemia de SIDA ao vivo e a cores e em directo (Bastos 1998a, 1999, 2010). Fiz experiências metodológicas de ancoragem num lugar e observação simultânea em outros bem distantes, antes ainda de terem posto a circular a nomenclatura de trabalho de campo multi-situado; trabalhei com vários níveis de comunidades e de integração, andei pelas fronteiras externas da disciplina, foi-me apontado que estava quase, ou mesmo, a sair dela, mas não era a primeira nem a última vez que corria esses riscos.

Esse ciclo teve como contraponto um outro em que procurei dar espessura temporal ao que interpretara para a epidemia de SIDA - e fui parar à medicina colonial e aos estudos de império. Estudar a SIDA através da perspectiva dos estudos de ciência deixara-me algumas perguntas: de onde vinha essa medicina de tiro-ao-alvo, de metáforas de guerra, de agentes infecciosos como invasores, de corpo como exército de sentinelas e soldados de combate, armamentário, arsenal, etc., e tudo o mais que povoa a linguagem da medicina, diagnóstico e tratamento das infecções? Assistira, a propósito da SIDA, à derrota de uma proposta de nova imunologia sistémica com implicações cognitivas e terapêuticas. Ganhara a medicina "de combate" - e a pergunta que se impunha era averiguar de onde vinha, em que processos cognitivos assentava o seu poder ontológico.

Essa pergunta levou-me aos primórdios da medicina tropical e ao seu entrosamento com o projecto colonial. Era minha tese que, na transição da teoria dos miasmas para a teoria dos micróbios, a prática da medicina em contexto de conquista fez preencher de metáforas militares a descrição dos processos vitais e patológicos, e com essas metáforas de guerra ficámos por muito tempo (Bastos 1998b). Esse ciclo de investigação, dedicado sobretudo a Goa (e.g., Bastos 2007) fez-me de novo transgredir algumas fronteiras convencionais da antropologia, pois levou-me de tal modo para o passado que a dado momento, mas não para sempre, tinha mais interlocutores na história da medicina e da ciência que na antropologia propriamente dita.

\section{IMPÉRIO E REVERSO}

Houve nesse percurso um momento interpretativo, o punctum de Roland Barthes (1980), que considero como um portal para o que faço hoje. ${ }^{4}$ Talvez

4 Devo a sugestão de pensar os momentos de salto interpretativo na antropologia histórica como punctum barthesiano às aulas de Ann Stoler na Advanced Summer School, "Along and Against Archival Grains", conjuntamente promovida pelos projectos "Colour of Labour" (ICS-ULisboa) e "Memoir" (CES-U. Coimbra) em 26-29 de Junho de 2018. 
não exactamente um portal de mudança instantânea, antes uma passagem lenta. Começou com a leitura de um obscuro par de artigos da década de 1920, escritos pelo também obscuro médico e antropólogo goês Germano Correia, sobre uma comunidade a que chamou eurafricanos, ou luso-angolenses, encontrada no planalto da Huíla, em Angola. Tratava-se de uma comunidade de descendentes de colonos portugueses que o autor usou como exemplo para uma espécie de manifesto eugenista, um apelo à pureza racial, a que noutra ocasião chamei "um luso-tropicalismo às avessas" (Bastos 2003). Tentei aprofundar a origem dessa comunidade, que se compunha exclusivamente de madeirenses e seus descendentes; encontrei narrativas de pioneirismo colonial, mas detectei também indicadores da fragilidade do projecto e a inconsistência deste com o propósito da colonização - o qual, como bem demonstraria Cláudia Castelo (2005), só foi organizado muito mais tarde e já na segunda metade do século XX. Fazendo curta uma longa história, argumentei que, mais que um projecto organizado de ocupação colonial, esta operação de transferência de madeirenses para o planalto da Huíla, no sul de Angola, tinha também como propósito criar uma rota alternativa àquela que muitos deles já seguiam em direcção às plantações de impérios concorrentes. Iam para o império britânico, sobretudo, numa rota descontínua mas prolongada para as plantações da Guiana e de algumas das ilhas (Ferreira 2006; Laurence 1965; Menezes 1986, 1992; Moore 1975; Rodney 1981; Spranger 2014); e iam também, naqueles anos, para as plantações do reino do Hawaii (Bastos 2018a, Caldeira 2010; Felix e Senecal 1978; Freitas 1979; Roll 1964; J. P. Silva 1996; R. Silva 2013; Spranger 2017).

Chegaremos ao Hawaii, mas demoremo-nos ainda um pouco mais na conexão Madeira-Angola e na sequência de encontros inesperados que me proporcionou: o encontro com o eugenismo e suprematismo branco, mais tarde sonegado por um regime que adoptou a ideologia luso-tropicalista da cordialidade, mistura, mestiçagem como diferenciador positivo; o encontro com imagens da colónia original de madeirenses na Huíla numa publicação de 1890 dedicada a convencer os portugueses de que era boa ideia ir integrar colónias em África, quando poucos o queriam fazer; o encontro com um registo de nascimento a bordo, sendo a bebé baptizada com o nome do barco, Maria Índia; a ida ao cenário da colonização, e o encontro inesperado com o túmulo de Maria Índia e a tentativa de escrever a sua história com estes dois únicos dados, nascimento e morte; o encontro com os seus descendentes, e tomar conhecimento do facto de ela ter já, quando nasceu, dois irmãos nascidos em Honolulu, mostrando que os fluxos e trânsitos eram muito mais amplos e multivariados do que eu alguma vez poderia imaginar (Bastos 2008, 2009, 2011). ${ }^{5}$

5 Agradeço a múltiplas pessoas a ajuda que permitiu estes encontros: à colega Rosa Melo e familiares, a pequena expedição à Humpata; à Rita, avó Maria da Paz, filha Maria Índia, pais, irmãos, [continua] 
Esta dimensão migratória era tanto mais surpreendente quanto era invisível na história e auto-representação predominante dos portugueses. Se na Madeira e Açores existe conhecimento, mesmo que diluído, dessas rotas de migração, no continente pouco mais se sabe que uma ou outra trivialidade sobre o ukulele havaiano ter raízes portuguesas; da Guiana nada se sabe, e sobre as Antilhas/Caraíbas houve um trabalho preliminar de Miguel Vale de Almeida (1997) que não foi ainda continuado.

Passei quase uma década a colectar tudo o que me permitisse ir mais longe neste assunto, entre fontes secundárias, livros e artigos sobre plantações de açúcar, sobre trabalho contratado após a abolição da escravatura, sobre etnicidades nas plantações, e sobre a Guiana e o Hawaii em particular. Nenhuma dessas fontes abordava directamente o tema que me interessava, mas muitas davam pistas que me permitiam formular o problema. Uma coisa sobressaía: tanto na Guiana como no Hawaii, os portugueses tinham-se constituído em categoria racializada. Não eram brancos, não eram negros, não eram indianos, não eram indígenas, mas também não eram abrangidos em categorias agregadoras como europeus, ibéricos, hispânicos, etc. Eram portugueses, ou poregee, ou podagee, ou portugee, ou portygee, ou portagee, tal como até há pouco era usado, depreciativamente, na Nova Inglaterra e em outros lugares (Azevedo 2010; Bastos 2019; Felix 2004; Harney 1990; Monteiro 2014; Naipaul 1996 [1962]; Roll 1964; R. Silva 2013).

A produção do açúcar foi em toda a história moderna a força motriz de grandes deslocamentos humanos, como mostra Mintz (1985) no seu magistral Sweetness and Power: o sabor doce vem carregado de sangue, suor e lágrimas, de grilhetas, escravização, passagens oceânicas, raptos, abusos, em suma, do complexo da plantação, essa máquina de gerar raça e motor das racializações (Bastos 2018a; Fields e Fields 2012; Thompson 1975, 2010). Assim aconteceu nas Caraíbas e no Brasil, onde foi com o açúcar que predominantemente se produziu a escravização e com ela a categoria "negro". Outras plantações, monoculturas de outros produtos capazes de transformar terra e trabalho em mercadorias lucrativas, como o café e, nos Estados Unidos, o algodão e tabaco, somaram-se ao açúcar nesse avolumar de máquinas de escravização e racialização.

Nalgumas situaçóes, o recrutamento de trabalho extravasou da escravização de africanos para outros grupos - a captura e rapto de ilhéus melanésios de Vanuatu e das Ilhas Salomão para as plantações nas Fiji e na Austrália, conhecidos como black birding; o recrutamento de trabalhadores da Índia, sob domínio britânico, com contratos (indenture) nem sempre transparentes para plantações britânicas em vários pontos do mundo, desde a Maurícia, no 
Índico, às Guianas e Trinidad, no Atlântico, às Fiji no Pacífico. ${ }^{6}$ Nalguns casos, o número de indianos e descendentes suplantou o de afrodescendentes, como na Guiana, e a categoria indentured, com a sua contrapartida racializada coolie, é frequentemente associada a descendentes da Índia. Mas houve muitos outros grupos assim traficados: centenas de milhares de chineses; dentro do império holandês, também javaneses; melanésios através do Pacífico; japoneses. E portugueses.

Situar e caracterizar os portugueses, que assim seguiram em grande número e circunstâncias nem sempre muito claras, está ainda por fazer, ou estamos a fazê-lo. No projecto "The Colour of Labour", algumas linhas de pesquisa incidem nas trajectórias de portugueses para plantações fora do império, incluindo a Guiana e o Hawaii. A Guiana é um caso fascinante, uma vez que entre o momento da Emancipação, em 1833-34 - na sequência da abolição do tráfico escravo, em 1807 - e a rotinização da importação massiva de indianos contratados, a partir dos anos 1850, houve um período em que a maioria da força do trabalho foi fornecida por madeirenses (Menezes 1986). Mas isso fica para outro dia. Hoje é do Hawaii que vou falar.

\section{PORTUGUESES NO HAWAII}

Reitero que o meu projecto actual não é sobre portugueses espalhados no mundo; tenta aliás ser o seu contrário e desessencializar a categoria "portugueses". Tal não impede que muitos interlocutores pensem que estou a trabalhar sobre portugueses no mundo, em modo essencialista, e me perguntem se os portugueses no Hawaii, ou na Guiana, mantiveram ou perderam os seus traços culturais. Respondo geralmente que "Portuguese" pode ser muita coisa. Além de gente, pode ser, precisamente, uma coisa: uma laranja, como em turco, ou uma variedade de salsicha, aliás chouriço, como no Hawaii. Em todas as ilhas do arquipélago, "Portuguese sausage" é uma vitualha, uma das escolhas de refeição no McDonald's e no Dunkin' Donuts, duas megacompanhias americanas cujos menus se adaptam aos gostos locais. É mesmo um sabor dos enlatados de Spam, outro favorito local. Ou uma sopa de feijão localmente apreciada,

6 Complementando o extraordinário mapeamento das viagens de escravizados produzido no âmbito de Transatlantic Slave Trade Data Base (< https://archive.slavevoyages.org/ > última consulta em outubro de 2019), o projecto UNESCO "Indentured Labour Routes" mapeia as viagens de trabalhadores vinculados - sobretudo da Índia - para as plantações de açúcar em diversos pontos do mundo, e promove a identificação das materialidades, situações, testemunhos e análises destas rotas; o projecto "The Colour of Labour" tem mantido um enriquecedor diálogo com este grupo - no que agradeço a Vijaya Teelock, da Universidade da Maurícia, Satyendra Peerthum, do Aapravasi Ghat Trust Fund, Maurícia, Maurits Hassankhan, da Universidade do Suriname, e Farzana Gounder, da Universidade Internacional do Pacífico, Nova Zelândia, bem como a Marcelo Moura Mello, da Universidade Federal da Bahia, a Nicholas Miller, Colette LePetitcorps, Marta Macedo e outros membros do "The Colour of Labour", a troca de pontos de vista e partilha de análises ao longo dos dois últimos anos. 
a "Portuguese bean soup". Ou é um estrangeiro em geral, como observa George Monteiro a propósito do livro Portygee, onde ninguém é sequer português e o "Portygee" do título até era espanhol (Lincoln 1920; Monteiro 2014). Ou é alguém, um grupo, umas pessoas, ligados ou não a poderes portugueses, que adoptam identificação dita portuguesa nas franjas do império, como observa António Hespanha (2019).

Esse processo de diferenciação, que congela e recorta uma categoria racializada - não apenas "étnica", mas hierarquizada -, está no centro do meu estudo. Não estamos atrás de essências identitárias, portanto, mas de categorias dinâmicas, produzidas em processos históricos e recriadas no quotidiano, incluindo como um tipo de produção cultural (Williams 1991) que adopta símbolos e ícones essencialistas. Tal é a discussão conceptual do projecto "The Colour of Labour” - mas hoje propus falar de açúcar e ananases, e de quem os produz, e não de abstracções teóricas.

Falemos então de açúcar e ananases, e de um modo que torna claro o porquê da longa incursão às confluências do trabalho de arquivo e de campo. O que levou tantos portugueses para o Hawaii, e por que razão está quase tudo esquecido, não fosse a trivialidade da associação cavaquinho/ukulele, repetida como o são as díades luso-nipónicas tempero/tempura ou obrigada/arikato, nem sempre verificadas ou assunto de pesquisa? ${ }^{7} \mathrm{Na}$ resposta a essa pergunta divergem o arquivo documental e a oralidade. No registo oral é frequente constar que a razão pela qual os madeirenses e açorianos vieram de tão longe, atravessando o Atlântico rumo a sul e depois o Pacífico rumo a norte até às longínquas ilhas do Hawaii, era porque sabiam de açúcar e ananases - de açúcar os madeirenses, que já a ilha o tinha produzido em grande escala no passado, e continuavam a cultivá-lo em menor escala; e de ananases os açorianos, que os cultivam até hoje. ${ }^{8} \mathrm{O}$ arquivo, veremos depois, não nos diz exactamente isso. De certo modo, quase indica o oposto, já que nem a cronologia dos cultivos no Hawaii o corrobora, nem os ilhéus vinham de uma plantação no Atlântico para uma sua réplica no Pacífico, nem as plantações do Hawaii precisavam prioritariamente de peritos em açúcar e ananases, mas sim de braços, pernas e corpos de trabalho em geral. É, porém, uma história plausível, como aquela com que comecei sobre o exílio de um castelo original atacado por febres na fronteira Portugal-Espanha. A etnografia é feita de todas estas histórias, todas valem na formação de uma memória que produz a identificação colectiva. Existe, no entanto,

7 Para o ukulele, que se tornaria um ícone do Hawaii, o parentesco com as suas contrapartidas portuguesas machete e braguinha está bem documentado, reportando-se ao trabalho influente dos carpinteiros Manuel Nunes, Augusto Dias e José Espírito Santo, bem como do afinador João Gomes, todos passageiros do Ravenscrag (Sousa 2019; Spranger 2017; Tranquada e King 2012).

8 Agradeço a Susana Caldeira e aos proprietários, trabalhadores e utilizadores do engenho de Ribeiro Seco, no Funchal, a visita proporcionada em plena actividade em Abril de 2019, e a Cláudia Ferreira Faria o apoio na visita ao engenho da Calheta e respectivo museu, também em Abril de 2019. 
uma cronologia de eventos, factualidades, deslocações, políticas migratórias, tráfico, a que se juntam significados, interpretações, reconstruções e vivências do passado no presente. A essas cronologias, espécie de trama que sustenta um tecido que se vai desenhado também do presente para o passado, vou referir-me na secção seguinte. Ouvindo o arquivo, como só se consegue com a ajuda do terreno e da confiança e partilha dos interlocutores.

\section{QUANTOS, QUANDO, POR QUE RAZÃO?}

As fontes secundárias sugerem que o número de portugueses transplantados para o Hawaii entre 1878 e 1913 ascende a 20.000 (Caldeira 2010; Felix e Senecal 1978; Spranger 2017), enquanto que a contagem levada a cabo pela Portuguese Genealogical and Historical Society of Hawaii a partir dos registos portuários, completada com artigos da imprensa local, sugere que o número ronda os 16.000, uma vez que alguns dos passageiros das últimas viagens eram espanhóis e devem ser subtraídos do cômputo global. ${ }^{9}$

Os números são calculados a partir das listas de passageiros dos diversos veleiros e vapores que transportaram os trabalhadores contratados e famílias. Existem vários factores de incerteza a complicar estes registos. Alguns passageiros embarcavam como clandestinos; outros custeavam a sua passagem e não se destinavam às plantações de açúcar, mas a ocupações comerciais e urbanas. Não entrando hoje nessa discussão, o certo é que se trata de um número muito elevado, tanto do ponto de vista da demografia das ilhas que deixaram, como do impacto à chegada.

Entre 1878 e 1889, ainda durante o reinado de David Kalakaua, chegaram ao porto de Honolulu 17 veleiros e vapores vindos das ilhas portuguesas com homens, mulheres e crianças maioritariamente destinados às plantações de açúcar. Foram eles o veleiro alemão Priscilla, a 30/9/1878 (116 dias de viagem da Madeira), com 120/180 pessoas (80 homens, 40 mulheres, 60 crianças); ${ }^{10} \mathrm{o}$ veleiro inglês Ravenscrag, a 23/8/1879 (123 dias de viagem da Madeira), com 419 pessoas (133 homens, 110 mulheres, 176 crianças); o veleiro inglês High Flyer, a 24/1/1880 (99 dias de viagem dos Açores), com 337 pessoas (109

9 A documentação da Portuguese Genealogical and Historical Society of Hawaii está disponível na sua sede na Liliha st., Honolulu, e foi gentilmente posta à nossa disposição nas visitas de 2017 e 2018. Uma transcrição fidedigna dos dados consta da página web "Portuguese immigration to Hawaii", $<$ https://en.wikipedia.org/wiki/Portuguese_immigration_to_Hawaii > (última consulta em Outubro de 2019).

10 As fontes são divergentes quanto ao número de passageiros do Priscilla. As análises mais recentes de Caldeira (2010) e Spranger (2017) apontam discrepâncias entre uma estimativa de 120 ou de 180. Apoiada na documentação do Funchal, Caldeira (2010: 262) sugere que o número é de 114 passageiros legais e seis clandestinos, portanto 120, e não os 180 listados em Honolulu. Não temos dados para ir mais longe que a especulação - clandestinos, nascimentos a bordo, contagem errada? 
homens, 81 mulheres e 147 crianças); de novo o High Flyer, a 2/5/1881 (130 dias de viagem dos Açores), com 352 pessoas (173 homens, 66 mulheres e 113 crianças); o veleiro inglês Suffolk, a 25/8/1881 (102 dias de viagem dos Açores), com 488 pessoas (206 homens, 100 mulheres e 182 crianças); o veleiro inglês Earl Delhausie, a 27/3/1 882 (1 13 dias de viagem dos Açores), com 322 pessoas (94 homens, 82 mulheres e 146 crianças); o vapor inglês Monarch, a 8/6/1882 (57 dias de viagem dos Açores), com 857 pessoas (202 homens, 197 mulheres e 458 crianças); o vapor inglês Hansa, a 15/9/1 882 (70 dias de viagem dos Açores), com 1177 pessoas (307 homens, 286 mulheres e 584 crianças); o vapor inglês Abergeldie, a 4/5/1 883 (62 dias de viagem dos Açores), com 938 pessoas (264 homens, 190 mulheres e 484 crianças); ${ }^{11}$ o vapor inglês Hankow, a 9/7/1883 (66 dias de viagem dos Açores e Madeira), com 1462 pessoas (427 homens, 317 mulheres e 718 crianças); o vapor inglês Bell Rock, a 1/1 1/1 883 (tempo de viagem desconhecido), com 1405 pessoas (396 homens, 294 mulheres e 715 crianças); o vapor inglês City of Paris, a 13/6/1884 (74 dias de viagem da Madeira e Açores), com 824 pessoas (295 homens, 199 mulheres e 330 crianças); o vapor recentemente tornado francês Bordeaux, a 3/10/1884 (72 dias de viagem a partir da Madeira), com 708 pessoas (273 homens, 173 mulheres e 262 crianças); ${ }^{12}$ o veleiro inglês Daca, a 19/1/1885 (114 dias de viagem), com 278 pessoas (63 homens, 50 mulheres e 165 crianças); o veleiro inglês Stirlingshire, a 4/3/1886 (1 12 dias de viagem da Madeira), com 467 pessoas (157 homens, 107 mulheres e 203 crianças); o veleiro inglês Amana, a 23/9/1886 (142 dias da Madeira), com 501 pessoas ( 146 homens, 116 mulheres e 239 crianças); e, por último, o veleiro inglês Thomas Bell, a 13/4/1888 (156 dias da Madeira), com 342 pessoas (117 homens, 62 mulheres e 163 crianças). ${ }^{13}$

Os navios a vapor podiam transportar mais rapidamente um número de pessoas muito superior ao das barcas e brigues; embora alguns destes chegassem aos 400 passageiros, em viagens de cerca de seis meses, os vapores podiam ultrapassar facilmente os mil passageiros e faziam-no em menos de dois meses. Entre 1883 e 1885 chegaram a Honolulu vários vapores repletos de trabalhadores portugueses, mas entre 1886 e 1889 foram retomadas as longas viagens de veleiro, mais penosas para os passageiros, mais económicas para os seus patrocinadores.

11 Estes valores não estão referidos em Spranger (2017), mas constam de Caldeira (2010: 262).

12 O Bordeaux teve uma viagem particularmente complexa, uma vez que fora adquirido por uma companhia francesa (Miller, no prelo), tinha novo comando e tripulação, foi sujeito a um controlo especial no porto do Funchal que levou a reduzir um grande número de passageiros considerados em excesso (alguns deles embarcariam na viagem seguinte da barca Daca, demorando muito mais para o destino, outros aceitaram uma compensação monetária) e, como se não bastasse, houve uma terrível epidemia de sarampo a bordo que dizimou mais de meia centena de crianças (ver Bastos 2018b; Caldeira 2010; Spranger 2017).

13 Estes dados estão maioritariamente baseados em Caldeira (2010: 262) e Spranger (2017: 2, 10). 
É precisamente da última viagem desta série, a do Thomas Bell, que temos um precioso diário de passageiros da autoria dos jovens madeirenses João Baptista d'Oliveira e Vicente Ornellas (D’Oliveira, Ornellas e Canario 1970). João trabalhara para ingleses no Funchal e dominava a língua, pelo que podia mediar a comunicação entre tripulantes e emigrantes; tinha uma percepção algo panóptica da vida a bordo. A conselho do imediato Kinnon, com quem fizera amizade, escreveu com o amigo Vicente um diário da viagem - felizmente para nós, já que esta modalidade literária, comum nas fontes inglesas, é rara entre os portugueses e caso único para as dezenas de viagens feitas entre as ilhas portuguesas e o Hawaii. Conta-nos do drama, comédia e tragédia da vida a bordo, em que nascem e morrem crianças, onde adultos também morrem, esperam, desesperam, choram, brincam, jogam cartas, cantam, dançam, fazem presépios (lapinhas), rezam, amam, têm sexo, traem, separam-se, juntam-se, casam, lutam; onde se enjoa, adoece, se encontram piolhos e carraças; onde os remédios prescritos constavam sobretudo de mais alimento, farinha de "sustância"; onde se luta por comida, onde os encarregados a trocam por favores sexuais, deixando a alguns nada mais que biscoito e café. Conta-nos a dureza da passagem do cabo Horn, o desembarque suspenso em Valparaíso, em função da epidemia de cólera que lá grassava, o desembarque conseguido em Iquique - onde oportunamente desapareceu o passageiro, antigo migrante em Demerara (Guiana), que criara a confusão de trazer a bordo mulher legítima e jovem amante e assim deixou ambas de uma só vez, ao que a última respondeu casando de seguida com um dos cozinheiros do barco. Dá-nos alguns momentos líricos sobre a alegria e espanto de encontrar espécies marinhas, albatrozes, tubarões, baleias, por vezes antecipando o banquete que poderiam proporcionar. A chegada é um culminar de júbilo e festa, não deixando, todavia, de ser entregue ao cônsul Canavarro uma lista com os problemas ocorridos na viagem.

Tão depressa não haveria chegada de ilhéus portugueses. Ganhando salários mais elevados, trazendo mais família - o que comportava custos acrescidos para a Junta de Imigração do Hawaii e para a associações de proprietários de plantações - e levantando maior resistência por parte das autoridades portuguesas (Coman 1978 [1903]: 37), madeirenses e açorianos deixaram de ser a primeira escolha para o trabalho de plantação, sendo substituídos por trabalhadores da Ásia, sobretudo do Japão. Entretanto, o Hawaii passa por grandes mudanças políticas: em 1893 é deposta a rainha Liliuokalani, irmã e sucessora de Kalakaua, falecido em 1891. A monarquia dá lugar a uma república liderada pelos principais donos de plantações; embora já tivessem grande influência junto da monarquia, os haoles (brancos, euro-americanos) passam a dominar oficialmente todas as esferas da política. Em 1898 o Hawaii é anexado aos Estados Unidos (Coffman 2016). Torna-se um "território", como hoje é o Porto Rico; passará a estado apenas em 1959. 
Em 1895, ainda durante o período de república pré-anexação, é retomada a promoção da emigração portuguesa. A seu favor argumentava o cônsul português António Canavarro, que se manteve no Hawaii depois do mandato original, em virtude de razões pessoais. ${ }^{14} \mathrm{O}$ primeiro desembarque da nova leva migrante dá-se em 4/4/1895, com a chegada do vapor alemão Braunfels a Honolulu, após 68 dias de viagem dos Açores, com 657 pessoas (274 homens, 124 mulheres e 259 crianças). A 13/9/1899, já com o Hawaii anexado aos Estados Unidos, chega o vapor inglês Victoria, após 67 dias de viagem da Madeira, com 343 pessoas (215 homens, 56 mulheres e 72 crianças). Segue-se o vapor neozelandês Warrimoo, a 24/12/1900, após dez dias de viagem de Vancouver, com 92 pessoas (60 homens, 14 mulheres e 18 crianças) ${ }^{15}$ logo seguido por outro vapor neozelandês, o Aorangi, a 16/2/1901, com oito dias de viagem também de Vancouver, trazendo 23 passageiros (9 homens, 7 mulheres e 7 crianças). ${ }^{16}$ As chegadas de viagem de longa distância das ilhas portuguesas são retomadas a 1/12/1906, com o vapor Surveric, vindo do Faial, nos Açores, e de Montevideu, no Uruguai, trazendo um total de 1324 passageiros (459 homens, 283 mulheres e 582 crianças). ${ }^{17}$

Entre 1907 e 1913 chega mais uma série de oito vapores, trazendo não apenas ilhéus mas também portugueses continentais e espanhóis: o vapor espanhol Heliopolis, a 26/4/1907 (dos Açores e de Malága, Espanha), com 2246 passageiros (608 homens, 554 mulheres e 1084 crianças); o Kumeric, a 27/6/1907 (da Madeira), com 1114 pessoas (333 homens, 306 mulheres e 475 crianças); ;8 o Swanley, a 12/12/1909 (da Madeira e Açores), com 868 pessoas (337 homens, 221 mulheres e 310 crianças); o Osteric/Orteric, a 13/4/1911 (da Madeira e previamente de Espanha e Portugal continental), com 1451 pessoas (547

14 Existiu um largo debate público comparando as vantagens e custos da contratação de portugueses ou japoneses e Canavarro envolveu-se na promoção dos portugueses (Arquivo Diplomático, Ministério dos Negócios Estrangeiros, Lisboa, Consulado de Portugal em Honolulu, Cx. 624, 1896/1913, Relatório Consular, 1907-1908).

15 Este barco não consta da lista actualizada de Spranger (2017), focada nas viagens de madeirenses, mas está incluído nos dados recolhidos em Honolulu por Caldeira (2010: 262) e pela Portuguese Genealogical Society (2013). Não sabemos exactamente qual era a origem destes passageiros embarcados em Vancouver.

16 Os dados relativos ao Aorangi foram acrescentados à página "Portuguese immigration to Hawaii" ( $<$ https://en.wikipedia.org/wiki/Portuguese_immigration_to_Hawaii $>$, última consulta em Outubro de 2019).

17 A viagem deste navio também não consta da compilação de 2017 de Ana Isabel Spranger, mas consta das demais listas. É uma das raras viagens das quais se conservou o registo do comandante sobre as ocorrências a bordo, permitindo-nos um conhecimento mais detalhado dos passageiros e tripulação (Official Log Book, Surveric, reg. Glasgow, Com. Shotton, July 71906 - July 26 1909, Kew National Archives, BT 165/429, 11065190$).$

18 A viagem do Kumeric é uma daquelas a que podemos aceder com mais pormenor, uma vez que o seu diário de bordo também foi mantido (Official Log Book, SS Kumerik, 124144, reg. Glasgow, Com. David Baird, November 81906 - March 3 1907, Kew National Archives, BT 165/313, 11065189 ). 
homens, 373 mulheres e 531 crianças); ${ }^{19}$ o Willesden, a 3/12/191 I (dos Açores e do continente português), ${ }^{20}$ com 1797 pessoas (639 homens, 400 mulheres e 758 crianças); o Harpalien, a 16/4/1912 (dos Açores e do continente português), com 1450 pessoas (496 homens, 328 mulheres e 626 crianças); novamente o Willesden, a 30/3/1913 (das ilhas e do continente português), com 1308 pessoas (491 homens, 377 mulheres e 440 crianças); e finalmente o Ascot, a 4/6/1913 (das ilhas e do continente português), com 1283 pessoas (424 homens, 327 mulheres e 532 crianças).

O impacto demográfico destas chegadas sequenciais foi notável, chegando os portugueses a ultrapassar os 10\% da população local de modo continuado (Adams 1937; Bastos 2018a; Caldeira 2010; Correa e Knowlton 1982; Dias 1981; Takaki 1983). Até 1930 é possível avaliar a sua proporção, uma vez que os portugueses eram classificados como categoria distinta. Maioritariamente em Oahu (a ilha mais povoada, embora não seja a maior, e onde se situa Honolulu), mas também nas ilhas de Maui, Kauai e Ilha Grande (Hawaii), os portugueses mantiveram-se um grupo diferenciado, com influência, associações de socorros mútuos, igrejas e jornais em língua portuguesa (Caldeira 2010; Felix e Senecal 1978; Freitas 1979; Knowlton 1960). Alguns seguiram com as suas vidas para a Califórnia, mas muitos mantiveram-se no Hawaii, ou a ele regressaram. Poucos regressaram às ilhas atlânticas (Spranger 2017).

Por que razão foram os ilhéus portugueses para o Hawaii, vindos de tão longe, com custos pessoais tão elevados para eles e custos monetários tão elevados para quem os patrocinava, a Junta de Imigração e a Associação de Plantadores de Açúcar do Hawaii? A resposta envolve açúcar, decerto, mas não tanto pela ancestral familiaridade dos madeirenses com o açúcar, embora essa exista e se saiba que, mesmo depois de a sua produção em massa na Madeira ter dado lugar a outras monoculturas, sobretudo da vinha, da cana-de-açúcar se manteve uma produção de pequena escala que chega até hoje e está sobretudo orientada para a produção de mel-de-cana, respectiva doçaria e rum. A conexão com o açúcar é sobretudo a de este ser uma produção de alto rendimento com necessidades vorazes de trabalho num contexto de declínio demográfico, como o do Hawaii no século XIX, e de políticas de povoamento que se entrelaçaram com as políticas de migração (Bastos 2018a; Beechert 1985; Jung 2006; Miller 2019, no prelo; Takaki 1983).

19 Ver Miller (no prelo), sobre as peripécias que os passageiros portugueses sofreram antes de embarcar, narradas na Ilustração Portuguesa (6/3/1911); ver também a interessante compilação das memórias de uma jovem passageira espanhola do Orteric por Patricia Ruiz Steele (2013).

20 Esta viagem do Willesden está também documentada (Official Log Book, Willesden, from London, Com. Cox (?), 23 September 1911 - 23 December 1912, Kew National Archives, BT 165/582, 11065191). 


\section{O CONTEXTO:}

\section{A PARTICULAR CRONOLOGIA DO HAWAII, DE REINO A PLANTAÇÃO}

O enlace do Hawaii com o açúcar ocorreu mais tarde que o das outras ilhas e faixas continentais ocupadas por potências coloniais europeias - Cuba, Jamaica, Barbados, Trinidad, Guianas, Brasil, Fiji, Maurícia, todos eles transformados pela monocultura, a paisagem rendida, e a sociedade reconfigurada em senhores coloniais e escravizados, uns e outros vindos de fora, a maioria da população indígena excluída ou dizimada. O Hawaii não era colónia de ninguém e só na segunda metade do século XIX se rendeu ao açúcar - mas este veio para ficar por muito tempo e transformar radicalmente a economia, sociedade e demografia das ilhas.

Uma breve nota sobre a história do Hawaii, fora das rotas tradicionais dos impérios. As ilhas estavam povoadas em consequência de viagens de longo curso de navegantes polinésios - das Marquesas, Taiti e outras - que vieram com famílias, animais, plantas. A comunicação com o Pacífico Sul foi entretanto interrompida e, apesar de poder ter havido contactos esporádicos com marinheiros e navegantes que os não registaram, ${ }^{21}$ as ilhas e os seus habitantes ficaram da fora da esfera de influência e conhecimento dos poderes europeus, asiáticos ou americanos até à visita da frota de James Cook, em 1778, durante a viagem em demanda da "passagem norte". O arquipélago não estava então politicamente unificado e organizava-se em chefaturas, até que o histórico líder Kamehameha desencadeou um processo de conquista que primeiro unificou a Ilha Grande (Hawaii), depois conquistou o grupo central (Maui, Molokai, Lennai) e Oahu, venceu a sangrenta batalha de Nuuanu, em 1795, e finalmente anexou as ilhas ocidentais de Kauai e Nihihau, em 1810. Iniciava-se uma dinastia que viveu as tensões, contradições e ambiguidades de um poder reconhecido interna e externamente (tinha relações diplomáticas com um grande número de países europeus, asiáticos e americanos) que, ao mesmo tempo, estava sujeito a fortes influências económicas e religiosas de fora. Pouco depois dos encontros com Cook - cujos episódios têm entretido debates antropológicos que aqui não tenho possibilidade de discutir -, chegavam já missionários e delegados de comércio de vários lugares; as elites locais e estrangeiras (haole) conviveram durante décadas numa complexa negociação de interesses e alianças matrimoniais. O cristianismo foi adoptado pela aristocracia havaiana

21 Seguimos aqui a consensual proposta de Daws (1968): poderá ter havido contactos, mas não ficaram registados. Note-se, porém, que nalguns sectores lusodescendentes no Hawaii se debate a possibilidade de o primeiro contacto europeu com as ilhas ter sido feito pelo navegador português João Caetano, ao serviço de Espanha, no século XVI (Felix and Senecal 1978, app. I; ver também trabalho escolar mimeografado de Catherine T. Medeiros, "The Portuguese in Hawaii: the first hundred years", s. d. - possivelmente do final dos anos 1960 ou princípios dos anos 70 -, p. 1, na posse da Portuguese Genealogical and Historical Society of Hawaii, consultado em 1 de Novembro de 2017). 
(alii) e por muitos populares, eliminando algumas tradições de separação (kapu, ou tabu). Entre as muitas mudanças operadas, há uma que tem um impacto central: o grande mahele, ou a divisão que permitiu a apropriação privada da terra, inicialmente pensada para defender os interesses locais, mas rapidamente posta ao serviço dos investidores estrangeiros. Em breve estaria no horizonte a tentação do lucro pelo açúcar. E assim viria a acontecer. A plantação de Koloa, na ilha de Kauai, tinha já sido desenvolvida experimentalmente em 1835 e provava dar bons resultados. Nos anos e décadas seguintes, o açúcar suplantaria o sândalo como mercadoria de exportação principal; suplantaria também o lugar do taro - o desejado e estimado tubérculo que está no centro da alimentação tradicional havaiana - como primeiro produto agrícola (MacLennan 2014; Daws 1968; Spranger 2017; Takaki 1983).

PLANTAÇÃO, TRABALHO, MIGRAÇÃO:

ILHÉUS PORTUGUESES, AÇÚCAR E ANANASES

Mas nem só a qualidade da terra, existência de água, propensão do clima e investimento de capital bastam para produzir açúcar; é necessário trabalho, e em enorme quantidade. Eram precisos muitos braços, pernas, troncos, força humana, discernimento, capacidades. Havia que plantar, cuidar, cortar, transportar, moer no engenho, tal como nas plantações escravistas do Brasil, da Jamaica, de Barbados, das Guianas. Mas, ao contrário do que acontecia nestas, estava já fora de questão a escravização e desumanização do tráfico humano que alimentara de mulheres e homens de África as plantações do Brasil e Caribe. Tão-pouco era viável o recurso à população local, entretanto em acelerada quebra demográfica. É de especular se terão existido no Hawaii experiências de recrutamento obscuro de ilhéus do Pacífico Sul e asiáticos, como veio a acontecer nas Fiji e na Austrália. Estando fora do circuito imperial britânico, não se verificou o engajamento de contratados da Índia. De onde importar trabalho, que viria sob a forma de pessoas, famílias, homens solteiros, línguas próprias, nações, etnicidades, foi uma questão intensamente debatida dentro do governo do Hawaii e entre os donos de plantações entretanto formadas.

Foi nesse contexto que se desenhou a possibilidade de atrair ilhéus portugueses. Vários factores levaram a essa escolha: a escassez demográfica local, o preconceito anti-asiático que marcou alguns governos do Hawaii durante o reinado de Kalakaua, e o interesse em atrair trabalhadores europeus para repovoamento. Um conjunto de circunstâncias leva aos portugueses entre os outros europeus. Existia já no arquipélago um grupo de residentes portugueses, maioritariamente chegados no trânsito baleeiro. Era comum os tripulantes dos baleeiros serem recrutados à força, ou mesmo raptados, e desertarem nos lugares por onde passavam - dispersando-se no Pacífico Sul e noutros 
lugares, concentrando-se no Hawaii, dada a escassez de outros arquipélagos no Pacífico Norte. Dos portugueses que tinham chegado ao Hawaii por estes meios, contavam-se algumas centenas. Um deles, Jason Parry (Jacintho Pereira), reivindicaria ter sugerido ao rei David Kalakaua que trouxesse trabalhadores portugueses. Uma outra circunstância que levantou o interesse nos portugueses foi o facto de um dos homens influentes no reino, o naturalista e médico alemão Hillebrandt, ter sido acolhido na Madeira nos anos 1870 e também ele recomendar a Kalakaua as qualidades dos madeirenses.

Acrescente-se a estas circunstâncias um outro elemento, quiçá mais importante: o facto de os madeirenses trilharem há muito rotas de saída, entre elas para as plantações da Guiana, em circuitos de mobilidade predominantemente supervisados por britânicos, dada a centralidade da Madeira nos circuitos de navegação internacional, a influência económica britânica na ilha, e a pressão demográfica interna - que, em tempos de escassez de alimentos, tinha levado a migrações clandestinas em massa e em circunstâncias terríveis.

Neste conjunto de factores, talvez não tenha sido a familiaridade com o cultivo do açúcar a razão central para recrutar madeirenses, mas o açúcar foi sem dúvida o motor de atracção para o Hawaii. Já o ananás foi um cultivo que veio por acréscimo, começando nas ilhas em modo exploratório em 1885 e só se tornando uma produção sistemática a partir de 1901, quando os portugueses já lá estavam em grande número. Não se exclui que os açorianos tenham também trabalhado nas plantações de ananás no Hawaii, quiçá usando conhecimentos prévios, tal como muitos madeirenses usaram a familiaridade com a cana-de-açúcar.

O ananás veio para ficar e tornou-se uma das culturas distintivas do Hawaii, embora de menor expressão económica e de muito menor impacto ecológico e social que a plantação de cana. Se a última plantação de açúcar, na ilha de Maui, deixou de produzir no ano de 2016, a produção do ananás continua ainda nalgumas ilhas. Em Ohau, a famosa Dole Plantation - que iniciou a produção de larga escala em 1901 - combina a produção com a espectacularização de si mesma: os visitantes são convidados a inúmeras actividades educativas, recreativas e culinárias em torno do tema do ananás, fazendo da visita uma fonte de renda. Já no Maui, a plantação do ananás deu lugar ao que alguns vêem como "plantação do século XXI:" a construção de enclaves de lazer, de clubes de golf a condomínios de aposentadoria paradisíacos. ${ }^{22}$

22 Agradeço a Colette LePetitcorps a troca de ideias a respeito deste fenómeno na Maurícia, e a Audrey Rocha Reed as visitas aos lugares de plantação de ananás em Maui e as discussões partilhadas sobre o assunto. 
PARA ALÉM DO ANANÁS E DO AÇÚCAR:

MEMÓRIAS FILTRADAS DA PLANTAÇÃO E PRODUÇÃO CULTURAL CONTEMPORÂNEA

Como vimos acima, não terá sido a familiaridade e especialização no cultivo da cana-de-açúcar e do ananás que levaram a contratar de tão longe os ilhéus portugueses para o Hawaii. Foi basicamente a necessidade de mão-de-obra e uma política de povoamento que favorecia o recrutamento de europeus, que tinha tentado também noruegueses, alemães, espanhóis, mas conseguiu estabilidade de fluxo apenas com os madeirenses e açorianos - um fluxo que saía caro à Junta de Imigração e aos donos das fazendas, que foi interrompido, e depois retomado.

O trabalho na plantação de açúcar tornou-se um meio, não um fim. Muitos suprimiram até da memória familiar a passagem pelos campos de cana-de-açúcar. Colectivamente, desenvolveu-se a tradição de que os portugueses tinham rapidamente ascendido a lunas (capatazes), embora, como noutras situações, essa qualificação fosse pouco frequente (Jung 2006). Passaram, sim, a outras ocupações: mantendo-se na plantação, como operadores de máquinas, marceneiros, ferreiros, por vezes reatando artes que já tinham da vida nas ilhas; mudando para contextos urbanos, estabelecendo casas comerciais e ofícios especializados; ou estabelecendo-se como pequenos agricultores. As dinâmicas de progressão económica e social tiveram configurações diferentes nas diferentes ilhas.

De comunidades compactas, endogâmicas, feitas de famílias extensas deslocadas para as plantações, os portugueses tornaram-se uma das referências da sociedade do século XX, caucasianos, eurodescendentes, mas não brancos, ou não brancos como os proprietários brancos (Geschwender, Carroll-Seguin e Brill 1988; Lassalle 2016), que por vezes eram da aristocracia indígena. Várias associações culturais, políticas e religiosas tomaram corpo nas comunidades, e em Honolulu imprimiam-se vários jornais em português. No tecido social havaiano do século XX, celebrado como exemplo de harmonia racial pelos sociólogos de Chicago Romanzo Adams (1937) e Andrew Lind (1938), e pelo mestre de ambos Robert Park, os portugueses constituem-se como um grupo entre outros, juntamente com chineses, japoneses, filipinos, coreanos, haoles (brancos), porto-riquenhos e havaianos. São objecto dos estudos que Adams e Lind dinamizam na recém-formada Universidade do Hawaii, em Manoa (ver Bastos 2018a, 2018b). Na sua produção cultural incluem-se festas do Espírito Santo, igrejas católicas, galos de Barcelos, malasadas, vinha-d'alhos, sopa de feijão, pão doce; celebra-se a memória construindo e mantendo uma “casa portuguesa" na Hawaii Plantation Village, e em vários outros museus de plantação; ou erguendo um símile de padrão de descobrimento, juntamente com calçada portuguesa, para comemorar os 100 anos da chegada do Priscilla; 
ou angariando fundos para mais um centro de cultura portuguesa em mais uma ilha; ou vibrando com os filmes Pukiki: The Portuguese Americans of Hawai ${ }^{i}$ (de Luís Proença, 2003), ou Portuguese in Hawaii (de Nelson Ponta-Garça, 2018); ou promovendo viagens de nostalgia a um lugar mitificado de origens, incluindo a Madeira, os Açores e o continente, sem faltar Fátima.

Esta complexa produção cultural, em tempos lida como marcador étnico, pode entreter-nos para sempre, mas há que propor linhas de ruptura analítica. E também no idílico Hawaii, onde todos convergem para celebrar a harmonia multi-racial e as incontáveis pontes e uniões entre grupos que no passado estavam separados, subjaz uma estrutura social diferenciada, desigual e historicamente violenta - uma quebra demográfica brutal, uma apropriação estrangeira das terras, uma importação de trabalho que a uns vilificava mais que a outros, diferenciando salários por grupos nacionais, hierarquizando-os, racializando-os. Podemos assim ir para além de uma caracterização de grupo e propor uma leitura de conjunto sobre as dinâmicas de diferenciação, criação de identidades, e hierarquização - ou seja, racialização - produzidas na plantação. Fica aqui o desafio.

\section{BIBLIOGRAFIA}

ADAMS, Romanzo, 1937, Interracial Marriage in Hawai i i. Nova Iorque, Macmillan.

ALMEIDA, Miguel Vale de, 1997, "Ser português na Trinidad: etnicidade, subjectividade e poder", Etnográfica, 1 (1): 9-31.

AZEVEDO, Rui Vitorino, 2010, "Not quite white: the ethno-racial identity of a Portagee", Op. Cit., 12: 19-34.

BARTHES, Roland, 1980, La chambre claire. Paris, Gallimard.

BASTOS, Cristiana, 1993, Os Montes do Nordeste Algarvio. Lisboa, Cosmos.

BASTOS, Cristiana, 1998a, "A política de produção de conhecimento e os movimentos de resposta à SIDA", Etnográfica, 2 (1): 15-53.

BASTOS, Cristiana, 1998b, "Germ theories in a colonial setting: medical theories and military practices in late nineteenth century Goa, India", EASST Review, 17 (4): 9-12.

BASTOS, Cristiana, 1999, Global Responses to AIDS: Science in Emergency. Bloomington, Indiana University Press.

BASTOS, Cristiana, 2003, "Um luso-tropicalismo às avessas: colonialismo científico, aclimação e pureza racial em Germano Correia”, em M.C. Ribeiro e A.P. Ferreira (orgs.), Fantasmas e Fantasias Imperiais no Imaginário Português Contemporâneo. Porto, Campo das Letras, 227-253.

BASTOS, Cristiana, 2007, "Medicina, império e processos locais em Goa, século XIX”, Análise Social XLII (182): 99-122. 
BASTOS, Cristiana, 2008, "Migrants, settlers and colonists: the biopolitics of displaced bodies", International Migration, 46 (5): 27-54.

BASTOS, Cristiana, 2009, "Maria Índia, ou a fronteira da colonização: trabalho migração e política no planalto sul de Angola", Horizontes Antropológicos, XV (31): 51-74.

BASTOS, Cristiana, 2010, "Tracking global flows and still moving: the ethnography of responses to AIDS”, em M. Melhuus, J.P. Mitchell e H. Wulff (orgs.), Ethnographic Practice in the Present. Oxford, Berghahn Books, 135-151.

BASTOS, Cristiana, 2011, "Trânsitos atlânticos, pacíficos e terrestres: a pequena grande história de Maria Índia”, em S. Arend, C. S. Rial e J. Pedro (orgs.), Diásporas, Mobilidades e Migrações. Florianópolis: Editora Mulheres, 69-78.

BASTOS, Cristiana, 2018a, "Portuguese in the cane: the racialization of labour in Hawaiian plantations”, em S. Aboim, P. Granjo e A. Ramos (orgs.), Changing Societies: Legacies and Challenges, vol. 1. Lisboa, Imprensa de Ciências Sociais, 65-96.

BASTOS, Cristiana, 2018b, "Febre a bordo: migrantes, epidemias e quarentenas", apresentado no simpósio "Mapeando Controvérsias Contemporâneas: Ecologia, Saúde, Biossegurança”, Porto Alegre, UfRGS, 12 de Julho de 2018.

BASTOS, Cristiana, 2019, "Lusotropicalism debunked, again: race, racism, and racialism in three Portuguese-speaking societies”, em W. Anderson, R. Roque e R. Ventura Santos (orgs.), Luso-Tropicalism and its Discontents: The Making and Unmaking of Racial Exceptionalism. Oxford, Berghahn, 243-264.

BEECHERT, Edward D., 1985, Working in Hawai $i$ : A Labor History. Honolulu, University of Hawai'i Press.

CALDEIRA, Susana, 2010, Da Madeira para o Hawai'i: A Emigração e o Contributo Cultural Madeirense. Funchal, CEHA.

CASTElo, Cláudia, 2005, Passagens para África: O Povoamento de Angola e Moçambique com Naturais da Metrópole. Porto, Afrontamento.

COFFMAN, Tom, 2016, Nation Within: The History of the American Occupation of Hawai'i (Revised Edition). Durham, Duke University Press.

COMAN, Katherine, 1978 [1903], "Portuguese labor contracts”, em J.H. Felix e P. Senecal (orgs.), The Portuguese in Hawaii. Honolulu, Centennial Edition, 35-37.

CORREA, Genevieve B., e Edgar W. KNOWLTON JR., 1982, "The Portuguese in Hawai'i”, Social Process in Hawai ' $i$, 29: 70-77.

DAWS, Gavan, 1968, Shoal of Time: A History of the Hawaiian Islands. Nova Iorque, Macmillan. DIAS, Eduardo Mayonne, 1981, "A presença portuguesa no Havai", separata do Boletim Cultural da Assembleia Distrital de Lisboa, 87 (1).

D’OLIVEIRA, João Baptista, Vicente D’ORNELLAS, e Lucile CANARIO, 1970, “Destination Sandwich Islands", Hawaiian Journal of History, 4: 3-52.

FELIX, Charles Reis, 2004, Through a Portagee Gate. Dartmouth, MA, Tagus Press.

FELIX, John Henry, e Peter SENECAL (orgs.), 1978, The Portuguese in Hawaii. Honolulu, Centennial Edition.

FERREIRA, Jo-Ann, 2006, “Madeiran Portuguese migration to Guyana, St. Vincent, Antigua and Trinidad: a comparative overview”, Portuguese Studies Review, 14 (2): 63-85.

FIELDS, Karen, e Barbara FIELDS, 2012, Racecraft: The Soul of Inequality in American Life. Nova Iorque, Verso.

FREITAS, Timothy Paul, 1979, From Captivity to Liberation: Literature of Madeiran Migration to Hawai' $i$. Cambridge, Harvard University, tese de doutoramento. 
GESCHWENDER, James A., Rita CARROLl-SEGUIN, e Howard BRILL, 1988, “The Portuguese and Haoles of Hawai 'i: implications for the origin of ethnicity", American Sociological Review, 53 (4): 515-527.

GORDILlO, Gaston, 2014, Rubble: The Afterlife of Destruction. Durham, Duke University Press.

HARNEY, Robert F., 1990, “Portygees and other Caucasians': Portuguese migrants and the racialism of the English speaking world”, em D. Higg (org.), Portuguese Migration in Global Perspective. Toronto, The Multiculatural Society of Ontario, 113-135.

HESPANHA, António, 2019, Filhos da Terra: Identidades Mestiças nos Confins da Expansão Portuguesa. Lisboa, Tinta-da-China.

JUNG, Moon-Kie, 2006, Reworking Race: The Making of Hawai 'i’s Interracial Labor Movement. Nova Iorque, Columbia University Press.

KNOWLTON JR., Edgar, 1960, “The Portuguese language press of Hawaii”, Social Process in Hawaii, 24: 89-99.

LADWIG, Patrice, et al., 2012, Fieldwork between Folders: Fragments, Traces, and the Ruins of Colonial Archives. Halle, Max Planck Institute for Social Anthropology.

LASSALLE, Melody, 2016, "Caucasian but not white: race and the Portuguese in Hawaii in the sugar plantation era", Your Island Routes, < http://www.researchjournal.yourislandroutes.com/20 16/07/caucasian-but-not-white-race-and-the-portuguese-in-hawaii/ > (última consulta em Outubro de 2019).

LAURENCE, K.O., 1965, "The establishment of the Portuguese community in British Guiana", Jamaican Historical Review, 5: 50-74.

LÉVI-STRAUSS, Claude, 1964-1971, Mythologiques. Paris, Plon.

LinCOLN, Joseph Crosby, 1920, The Portygee. Nova Iorque e Londres, D. Appleton.

LIND, Andrew, 1938, An Island Community: Ecological Succession in Hawai i. Chicago, The University of Chicago Press.

MacLENNAN, Carol, 2014, Sovereign Sugar. Honolulu, University of Hawai'i Press.

MENEZES, Mary Noel, 1986, Scenes from the History of the Portuguese in Guyana. Londres, Victoria Printing Works.

MENEZES, Mary Noel, 1992, The Portuguese of Guyana: A Study in Culture and Conflict. Anand, Gujarat, Anand Press.

MILLER, Nicholas B., 2019, "Trading sovereignty and labour: the consular network of nineteenth-century Hawai' $\mathrm{i}$ ”, The International History Review, DOI: 10.1080/0707533 2.2019 .1586747

MILLER, Nicholas B., no prelo, "Crossing seas and labels: Hawaiian contracts, British passenger vessels and Portuguese labor migrants, 1878-1911", Portuguese Literary and Cultural Studies.

MINTZ, Sidney, 1985, Sweetness and Power: The Place of Sugar in Modern History. Londres, Penguin.

MONTEIRO, George, 2014, "Essay: From Portingale to 'Portugee' ", Portuguese American Journal, < https://portuguese-american-journal.com/essay-from-portingale-to-portugee-by-ge orge-monteiro/ > (última consulta em Outubro de 2019).

MOORE, Brian, 1975, The social impact of Portuguese immigration into British Guiana after emancipation, Boletín de Estudios Latinoamericanos y del Caribe, 19: 3-15.

NAIPAUL, V.S., 1996 [1962], The Middle Passage: Impressions of Five Colonial Societies. Londres, Picador. 
RODNEY, Walter, 1981, A History of the Guyanese Working People, 1881-1905. Baltimore, Johns Hopkins University Press.

ROLL, Elvira Osorio, 1964, Hawaii’s Kohala Breezes. Nova Iorque, Exposition Press.

SILVA, Francisco Vaz da, 2016, "Charles Perrault and the evolution of 'Little Red Riding Hood' ", Marvels \& Tales, 30 (2): 167-190.

SILVA, Joaquim Palminha, 1996, Portugueses no Havaí: Sécs. XIX e XX (da Imigração à Aculturação). Ponta Delgada, Presidência do Governo Regional dos Açores.

SILVA, Reinaldo, 2013, "From the top of the racial pyramid in Hawai' $\mathrm{i}$ : demonizing the Hawaiian Portuguese in Elvira Osorio Roll's fiction", Interdisciplinary Journal of Portuguese Diaspora Studies, 2: 7-31.

SOUSA, Élia de, 2019, “Da braguinha ao ukulele: uma viagem de 140 anos”, apresentado no seminário "A Emigração Madeirense e Açoriana para o Hawaii", Casa da Madeira nos Açores, Ponta Delgada, 6/4/2019.

SPRANGER, Ana Isabel, 2014, "Guiana Inglesa”, Dicionário Enciclopédico Aprender Madeira, $<$ http://aprenderamadeira.net/guiana-inglesa/ > (última consulta em Outubro de 2019). SPRANGER, Ana Isabel, 2017, "Havai, emigração para o", Dicionário Enciclopédico Aprender Madeira, < http://aprenderamadeira.net/havai-emigracao-para-o/ > (última consulta em Outubro de 2019).

STEELE, Patricia Ruiz, 2013, The Girl Immigrant. Casa Grande, AZ, Plumeria Press.

STOLER, Ann Laura, 1995, Race and the Education of Desire: Foucault's History of Sexuality and the Colonial Order of Things. Durham, Duke University Press.

STOLER, Ann Laura, 2010, Along the Archival Grain: Epistemic Anxieties and Colonial Commonsense. Princeton, Princeton University Press.

TAKAKI, Ronald, 1983, Pau Hana: Plantation Life and Labor in Hawai'i 1835-1920. Honolulu, University of Hawai'i Press.

ThOMPSON, Edgar T., 1975, Plantation Societies, Race Relations and the South: The Regimentation of Populations. Durham, Duke University Press.

THOMPSON, Edgar T., 2010, The Plantation. Columbia, SC, The University of South Carolina Press.

TRANQUADA, Jim, e John KING, 2012, The 'Ukulele: A History. Honolulu, The University of Hawai'i Press.

WILliAMS, Brackette F., 1991, Stains on My Name, War on My Veins: Guyana and the Politics of Cultural Struggle. Durham, Duke University Press. 